\title{
Metformin-suppressed differentiation of human visceral preadipocytes: Involvement of microRNAs
}

\author{
KOJI FUJTAA ${ }^{1}$, HISAKAZU IWAMA ${ }^{2}$, KYOKO OURA ${ }^{1}$, TOMOKO TADOKORO $^{1}$, KAYO HIROSE $^{1}$, \\ MIWAKO WATANABE ${ }^{1}$, TEPPEI SAKAMOTO ${ }^{1}$, AKIKO KATSURA ${ }^{1}$, SHIMA MIMURA ${ }^{1}$, \\ TAKAKO NOMURA $^{1}$, JOJI TANI ${ }^{1}$, HISAAKI MIYOSHI ${ }^{1}$, ASAHIRO MORISHITA ${ }^{1}$, HIROHITO YONEYAMA ${ }^{1}$, \\ KEIICHI OKANO ${ }^{3}$, YASUYUKI SUZUKI ${ }^{3}$, TAKASHI HIMOTO ${ }^{1}$ and TSUTOMU MASAKI $^{1}$ \\ ${ }^{1}$ Department of Gastroenterology and Neurology, Faculty of Medicine, ${ }^{2}$ Life Science Research Center, \\ ${ }^{3}$ Department of Gastroenterological Surgery, Faculty of Medicine, Kagawa University, Miki, Kagawa 761-0793, Japan
}

Received April 8, 2016; Accepted August 31, 2016

DOI: $10.3892 / \mathrm{ijmm} .2016 .2729$

\begin{abstract}
Visceral adipose tissue contributes to the pathophysiology of metabolic syndrome. Metformin has been reported to suppress lipogenesis in a murine preadipocyte cell line. However, the effect of metformin on the differentiation of human visceral adipose tissue remains unknown. MicroRNAs (miRNAs or miRs) have been suggested as therapeutic targets because of their involvement in the differentiation and maturation of fatty cells. The aim of this study was to determine whether metformin suppresses the differentiation of human preadipocytes and to identify miRNAs associated with the regulation of lipid metabolism. Human visceral preadipocytes (HPrAD-vis) were preincubated in growth media and then cultured with differentiation media containing metformin for 1 or 2 weeks. Adipogenic differentiation of the cells was assessed by Oil Red O staining, and soluble adiponectin in the culture media was measured using an enzyme-linked immunosorbent assay. Cell proliferation was assessed using a WST- 8 assay, and the gene and protein expression of peroxisome proliferator-activated receptor $\gamma($ PPAR $\gamma)$ and CCAAT-enhancer-binding protein $\alpha(\mathrm{C} / \mathrm{EBP} \alpha)$ was determined by RT-qPCR and western blot analysis, respectively. miRNAs were profiled using human miRNA Oligo chips after total RNA was extracted and labeled. Oil Red O staining showed that metformin suppressed the accumulation of lipid droplets in HPrAD-vis cells. The adiponectin concentration
\end{abstract}

Correspondence to: Professor Tsutomu Masaki, Department of Gastroenterology and Neurology, Faculty of Medicine, Kagawa University, Ikenobe 1750-1, Miki, Kagawa 761-0793, Japan

E-mail: tmasaki@med.kagawa-u.ac.jp

Abbreviations: ELISA, enzyme linked immunosorbent assay; PCR, polymerase chain reaction; SDS-PAGE, sodium dodecyl sulfate-polyacrylamide gel electrophoresis

Key words: visceral adipocyte, differentiation, microRNA, metabolic syndrome in the culture media was also decreased in metformin-treated cells. The WST-8 assay revealed no effect on proliferation or growth inhibition following metformin treatment, although metformin suppressed the expression of PPAR $\gamma$ and $\mathrm{C} / \mathrm{EBP} \alpha$. miRNA profiling further revealed differences between the metformin-treated group and control HPrAD-vis cells. Thus, the findings of the present study demonstrated that metformin suppressed the differentiation of human preadipocytes in vitro and altered the miRNA profile of these cells. Thus, the miRNAs whose expression levels were altered by metformin may contribute to the observed suppression of HPrAD-vis cell differentiation.

\section{Introduction}

Visceral adipose tissue contributes to the pathophysiology of metabolic syndrome, which includes conditions such as insulin resistance, hypertension, hyperlipidemia and hyperuricemia $(1,2)$. The basic strategy to treat metabolic syndrome is diet and exercise to prevent patients from cardiovascular disease and diabetes mellitus (3). However, visceral obesity negates efforts to cut down on the energy supply and metabolize excess energy (1). Medication or surgery is considered when lifestyle alteration fails, although the indication for bariatric surgery is limited to severely obese cases and those complicated with organ failure (4). Thus, the majority of metabolic syndrome cases with no response to diet and exercise are treated with medication.

Metformin is an oral biguanide drug that was introduced into clinical practice in the 1950s for the treatment of type 2 diabetes (5). Although metformin has been reported to suppress lipogenesis in a murine preadipocyte cell line, in contrast to thiazolidine, which induces the maturation of preadipocytes $(6,7)$, the effect of metformin on human visceral adipose tissue has not been clearly demonstrated.

MicroRNAs (miRNAs or miRs) have been suggested as therapeutic targets in metabolic syndrome due to their role in the maturation of fat cells and the differentiation of adipocytes from mesenchymal stromal stem cells (8-10).

The aim of the present study was to determine whether metformin suppresses the differentiation of human 
preadipocytes and to identify miRNAs associated with the regulation of lipid metabolism in these cells.

\section{Materials and methods}

Reagents. Primary antibodies for peroxisome proliferator-activated receptor $\gamma(\operatorname{PPAR} \gamma)$ (cat. no. ab27649) and CCAAT-enhancer-binding protein $\alpha(\mathrm{C} / \mathrm{EBP} \alpha)$ (cat. no. ab40761) were supplied by Abcam (Cambridge, UK). The primary antibody for $\beta$-actin (cat. no. AC-15) was obtained from Sigma Aldrich (St. Louis, MO, USA). The primers and probes used in RT-qPCR for PPAR $\gamma$ (Assay ID: Hs01115513_m1), $\mathrm{C} / \mathrm{EBP} \alpha$ (assay ID: Hs00269972_s1) and $\beta$-actin (assay ID: Hs01060665_g1) were supplied by Life technologies (Carlsbad, CA, USA).

Cell line and culture. Poietics ${ }^{\mathrm{TM}}$ human visceral preadipocytes (HPrAD-vis) were purchased from Lonza (Walkersville, MD, USA). Cells were plated and subcultured according to the manufacturer's instructions. Briefly, the cells were suspended in growth media at $1 \times 10^{5}$ cells $/ \mathrm{ml}$, and $1.5 \mathrm{ml}$ of the cell suspension was seeded in 6-well dishes. The cells were incubated for $24 \mathrm{~h}$. For the treated group, $1.5 \mathrm{ml}$ of differentiation media (containing insulin, dexamethasone, indomethacin and isobutylmethylxanthine) including 2 or $10 \mathrm{mM}$ metformin was added to the growth media in each well, yielding final concentrations of metformin of 1 and $5 \mathrm{mM}$, respectively. As a control, $1.5 \mathrm{ml}$ of differentiation media without metformin was added to the control cells in growth media. Cells or media were harvested at the indicated time points.

Oil Red $O$ staining. Adipogenic differentiation of the cells was assessed with Oil Red $\mathrm{O}$ staining as previously described (11). The cells were washed with PBS and fixed in $4 \%$ paraformaldehyde for $10 \mathrm{~min}$. The cells were then washed with $3 \%$ isopropanol, followed by staining with newly filtered Oil Red O staining solution for $10 \mathrm{~min}$. After washing with distilled water, the cells were destained in $100 \%$ isopropanol for $15 \mathrm{~min}$. The stained area was measured using Image J (NIH, Bethesda, MD, USA).

Enzyme-linked immunosorbent assay for adiponectin in culture media. The adiponectin concentration in the culture media was measured using an enzyme-linked immunosorbent assay with human Adiponectin/Acrp30 (R\&D systems, Minneapolis, MN, USA) (12). The assay was performed according to the manufacturer's protocol.

Cell proliferation assay. Cell proliferation was evaluated using a WST-8 assay, as previously described $(13,14)$. Briefly, cell growth was measured with $10 \%$ WST- 8 (Dojindo Laboratories, Tokyo, Japan) in a microplate reader according to the absorbance at $450 \mathrm{~nm}$ at the indicated time point.

$R T-q P C R$. Reverse-transcription and qPCR were performed to measure changes in messenger RNA (mRNA) expression following metformin treatment. Taqman ${ }^{\circledR}$ Gene Expression Assays (Life Technologies) were used to determine the expression level of mRNAs, and $\beta$-actin was used as an internal control. mRNAs were reverse transcribed using the Taqman ${ }^{\circledR}$
RNA Reverse Transcription kit (Life Technologies) according to the manufacturer's protocol. Briefly, total RNA was extracted using the RNeasy Mini kit (Qiagen, Venlo, The Netherlands) and diluted to $1.0 \mathrm{ng} / \mu \mathrm{l}$. Reverse transcription was performed in a $20 \mu \mathrm{l}$ reaction volume consisting of $10 \mu \mathrm{l}$ of RNA, $2 \mu \mathrm{l}$ of 10X RT random primers and $8 \mu \mathrm{l}$ of reverse transcription master mix. As a result, $0.5 \mathrm{ng} / \mu 1$ of cDNA was produced per tube. The PCR reaction was performed in a final volume of $20 \mu \mathrm{l}$, consisting of $2 \mu \mathrm{l}$ of cDNA $(0.5 \mathrm{ng}), 1 \mu \mathrm{l}$ of $20 \mathrm{X}$ qPCR assay mix, $7 \mu \mathrm{l}$ of nuclease-free water and $10 \mu \mathrm{l}$ of Taqman ${ }^{\circledR}$ Fast Universal Master mix according to the manufacturer's protocol. The cDNA was amplified and quantified using StepOnePlus ${ }^{\mathrm{TM}}$ (Life Technologies). The mRNA expression levels were standardized to $\beta$-actin.

Western blot analysis. The cell lysates were processed as previously described (15). All the steps were carried out at $4^{\circ} \mathrm{C}$. Protein concentrations were measured using a spectrophotometer Nano Drop 2000 (Thermo Fisher Scientific Inc., Wilmington, DE). The samples were electrophoresed using $10 \%$ SDS-PAGE gels, and the proteins were transferred to nitrocellulose membranes. The membranes were then incubated with primary antibodies after being blocked and incubated with horseradish peroxidase (HRP)-conjugated secondary antibodies. Immunoreactive proteins were visualized with an enhanced chemiluminescence detection system (PerkinElmer, San Jose, CA, USA) on X-ray film, as previously described $(13,14)$.

miRNA array analysis. Total RNA of cultured cells was extracted using the miRNeasy Mini kit (Qiagen) as previously described $(13,14,16-21)$. The samples were labeled using a miRCURY Hy3 Power Labeling kit (Exiqon, Vedbaek, Denmark) and hybridized onto a human miRNA Oligo chip, version 14.0 (Toray Industries Inc., Tokyo, Japan). Scanning was conducted using a 3D-Gene Scanner 3000 (Toray Industries Inc.). 3D-Gene extraction software (ver. 1.2, Toray Industries Inc.) was used to read the raw intensity of the image. The raw data were analyzed with GeneSpringGX ver. 10.0 (Agilent Technologies, Santa Clara, CA, USA) and quantile normalized (22). The fold-changes in miRNA expression level between the treated and control groups were calculated. Hierarchical clustering was accomplished using the furthest neighbor method and Pearson's product-moment correlation coefficients as a metric.

\section{Results}

Metformin suppresses the differentiation of preadipocytes with no proliferative effect on the cells. We studied the effect of metformin on the maturation of HPrAD-vis cells through morphological analysis with Oil Red O staining. Metformin (1 and $5 \mathrm{mM}$ ) significantly reduced lipid droplet accumulation in preadipocytes, as shown in Fig. 1A and B.

We also analyzed adiponectin secretion by measuring the concentration in the culture media. As shown in Fig. 1C, metformin decreased the adiponectin concentration on days 7 and 14 of culture. However, according to the WST- 8 assay, metformin did not have any proliferative or growth-inhibitory effect on the cells. 


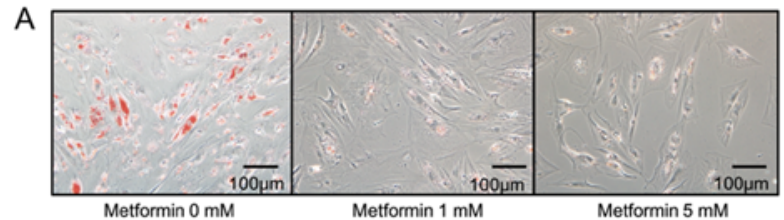

B

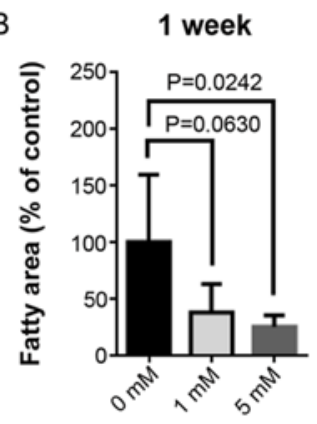

Dose (metformin)

C

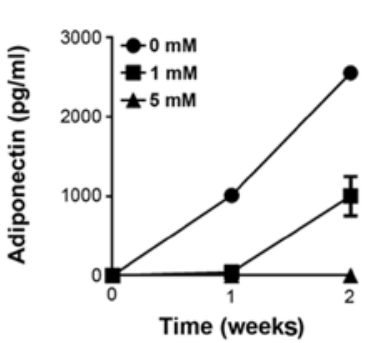

$\mathrm{E}$

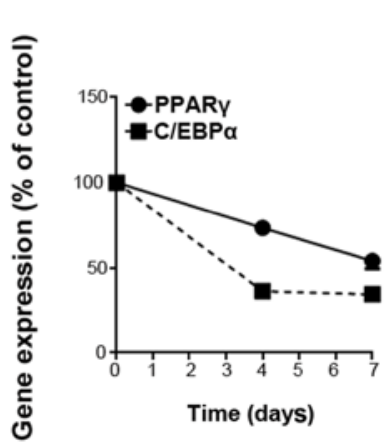

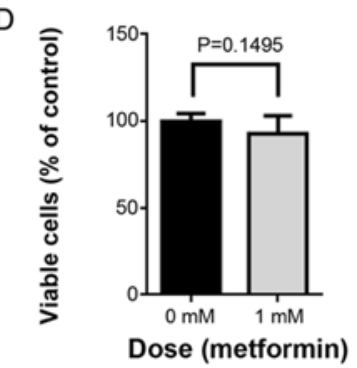

2 weeks

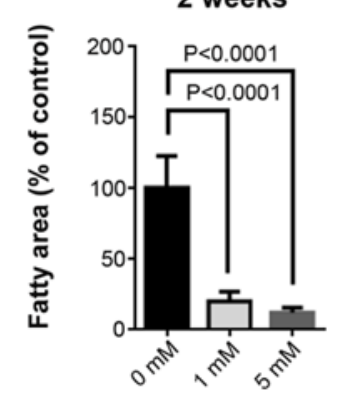

Dose (metformin)

$\mathrm{F}$

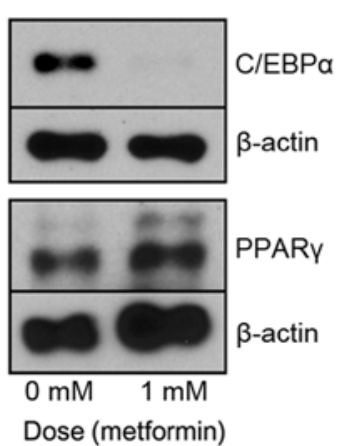

Figure 1. Metformin suppresses the maturation of human visceral preadipocytes with no suppression of cell growth. (A) Metformin suppresses lipid droplet accumulation in human visceral preadipocytes. Oil Red O staining of HPrAD-vis cells was performed after 2 weeks of culture with or without metformin. The stained area was reduced in metformin-treated cells compared to non-treated cells, x200. (B) The relative stained area of metformin-treated cells and non-treated cells. Cells were cultured for 1 or 2 weeks with or without metformin. The stained areas per $\times 200$ field were measured using Image J. (C) Adiponectin secretion from HPrAD-vis cells is decreased following treatment with metformin. The cells were cultured for 1 or 2 weeks with or without metformin $(n=3)$. The adiponectin concentration in the culture media was determined by ELISA with the specific antibody Acrp30. (D) Metformin did not suppress the growth of fatty cells. Cells were incubated with or without metformin for 1 week. Cell proliferation was measured using a WST-8 assay $(n=6)$. (E) Genes involved in the differentiation and maturation of preadipocytes are downregulated by metformin. Cells were incubated for 1 week with or without metformin. The relative expression of PPAR $\gamma$ and $\mathrm{C} / \mathrm{EBP} \alpha$ in metformin-treated cells compared to non-treated cells was determined using RT-qPCR with relative quantification $(n=3)$. $\beta$-actin was used as an internal control gene. (F) Effect of metformin on gene expression was confirmed by western blot analysis. The cells were incubated for 1 week with or without metformin. The protein expression level of $\mathrm{C} / \mathrm{EBP} \alpha$ decreased after treatment. HPrAD-vis, human visceral preadipocytes; ELISA, enzymelinked immunosorbent assay; PPAR $\gamma$, peroxisome proliferator-activated receptor $\gamma ; \mathrm{C} / \mathrm{EBP} \alpha, \mathrm{CCAAT}$-enhancer-binding protein $\alpha$.

Table I. Statistical results and chromosomal locations of miRNAs in HPrAD-vis cells treated with $5 \mathrm{mM}$ metformin for 1 week compared to control cells $(\mathrm{P}<0.05)$.

\begin{tabular}{|c|c|c|c|c|}
\hline Name & $\begin{array}{c}\text { Fold-change } \\
\text { (treated/control) }\end{array}$ & SD & P-value & Location \\
\hline miR-664a-5p & 2.57 & 0.406 & 0.0090 & 1 \\
\hline $\operatorname{miR}-3687^{a}$ & 2.34 & 0.910 & 0.0229 & 21 \\
\hline miR-4664-3p & 2.30 & 0.904 & 0.0153 & 8 \\
\hline $\operatorname{miR}-1246^{a}$ & 1.78 & 0.363 & 0.0107 & 2 \\
\hline miR-4783-3p & 1.74 & 0.183 & 0.0010 & 2 \\
\hline miR-4656 & 1.58 & 0.266 & 0.0019 & 7 \\
\hline miR-1539 & 0.64 & 0.362 & 0.0136 & 18 \\
\hline $\operatorname{miR}-148 b-3 p^{a}$ & 0.64 & 0.198 & 0.0109 & 12 \\
\hline miR-4638-3p & 0.63 & 0.165 & 0.0170 & 5 \\
\hline miR-515-5p & 0.62 & 0.325 & 0.0205 & 19 \\
\hline miR-134 & 0.61 & 0.273 & 0.0313 & 14 \\
\hline miR-939-5p & 0.60 & 0.239 & 0.0360 & 8 \\
\hline $\operatorname{miR}-378 a-3 p^{a}$ & 0.54 & 0.069 & 0.0004 & 5 \\
\hline $\operatorname{miR}-378 i^{a}$ & 0.49 & 0.090 & 0.0115 & 22 \\
\hline $\operatorname{miR}-422 a^{a}$ & 0.45 & 0.066 & 0.0068 & 15 \\
\hline miR-425-3p & 0.42 & 0.185 & 0.0420 & 3 \\
\hline miR-661 & 0.42 & 0.307 & 0.0244 & 8 \\
\hline $\operatorname{miR}-615-5 p$ & 0.40 & 0.233 & 0.0481 & 12 \\
\hline miR-3160-3p & 0.21 & 0.019 & 0.0037 & 11 \\
\hline
\end{tabular}

amiRNAs were matched to miRNAs extracted from cells treated with $5 \mathrm{mM}$ metformin for 2 weeks as shown in Table II. miRNAs, microRNAs; HPrAD-vis, human visceral preadipocytes; SD, standard deviation.

We then examined whether the expression levels of key genes involved in adipocyte differentiation (PPAR $\gamma$ and $\mathrm{C} \mathrm{EBP} \alpha$ ) were altered by metformin. The mRNA expression of PPAR $\gamma$ and $\mathrm{C} / \mathrm{EBP} \alpha$ was downregulated by metformin treatment on day 7 (Fig. 1D). Downregulation of $\mathrm{C} / \mathrm{EBP} \alpha$ translation was confirmed by western blot analysis (Fig. 1E). These experiments were repeated three times, and identical results were obtained.

Differences in miRNA expression in HPrAD-vis cells cultured in vitro with and without metformin. Using custom microarrays, we analyzed the expression of human miRNAs in HPrAD-vis cells treated with or without metformin. As shown in Table I, for HPrAD-vis cells treated with or without $5 \mathrm{mM}$ metformin, 6 miRNAs were significantly upregulated after 1 week of metformin treatment, while 13 miRNAs were downregulated. After 2 weeks of $5 \mathrm{mM}$ metformin treatment, 27 miRNAs were significantly upregulated and 6 miRNAs were downregulated compared to the control (Table II). As shown in Tables I and II, 2 upregulated miRNAs (miR-3687 and miR-1246), 4 downregulated miRNAs including miR-378 family members were observed in the cells cultured for 1 and 2 weeks with metformin. The expression level of miR-1246 increased in a time-dependent manner. 
Table II. Statistical results and chromosomal locations of miRNAs in HPrAD-vis cells treated with $5 \mathrm{mM}$ metformin for 2 weeks compared to control cells $(\mathrm{P}<0.05)$.

Fold-change

Name (treated/control)

miR-1246

miR-600

miR-1238-5p

$\operatorname{miR}-3687^{\mathrm{a}}$

miR-1185-1-3p

miR-1229-5p

miR-671-5p

miR-371a-5p

miR-5006-5p

miR-651

miR-4465

miR-4756-5p

miR-4632-3p

miR-643

miR-513a-5p

miR-1292-5p

miR-4714-3p

miR-1185-2-3p

miR-1273a

miR-202-5p

miR-4747-3p

miR-4787-3p

miR-4321

miR-1343

miR-4257

miR-4688

miR-675-5p

miR-148b-3p ${ }^{a}$

miR-22-5p

miR-145-5p

miR-4697-3p

miR-581

miR-4443

miR-224-5p

miR-143-3p

miR-335-5p

miR-484

miR-339-5p

miR-223-3p

miR-652-3p

miR-1255a

miR-422a $\mathrm{a}^{\mathrm{a}}$

miR-378b

miR-135b-5p

miR-548b-5p

miR-302e

miR-378a-3p ${ }^{a}$

miR-3616-5p

let- $7 \mathrm{e}-3 \mathrm{p}$
2.08

2.03

2.02

1.99

1.97

1.93

1.91

1.88

1.87

1.85

1.85

1.77

1.75

1.72

1.71

1.66

1.63

1.62

1.60

1.58

1.57

1.51

0.65

0.64

0.64

0.61

0.59

0.59

0.59

0.58

0.56

0.55

0.54

0.52

0.48

0.47

0.46

0.45

0.43

0.43

0.42

0.41

0.41

0.40 $\begin{array}{ll}0.160 & 0.0017\end{array}$

$\begin{array}{ll}0.314 & 0.0209\end{array}$

$0.241 \quad 0.0225$

$\begin{array}{lll}0.306 & 0.0339\end{array}$

$\begin{array}{lll}0.497 & 0.0448\end{array}$

$0.222 \quad 0.0079$

$0.208 \quad 0.0352$

$\begin{array}{ll}0.584 & 0.0251\end{array}$

$\begin{array}{lll}0.397 & 0.0319\end{array}$

$\begin{array}{ll}0.259 & 0.0039\end{array}$

$0.416 \quad 0.0155$

$0.693 \quad 0.0408$

$0.271 \quad 0.0359$

0.3690 .0236

$0.437 \quad 0.0495$

$0.239 \quad 0.0134$

$\begin{array}{lll}0.356 & 0.0431\end{array}$

$\begin{array}{ll}0.267 & 0.0262\end{array}$

$\begin{array}{ll}0.233 & 0.0008\end{array}$

$0.149 \quad 0.0014$

$0.152 \quad 0.0014$

$0.041 \quad 0.0003$

$0.064 \quad 0.0285$

$0.049 \quad 0.0007$

$\begin{array}{lll}0.067 & 0.0014\end{array}$

$\begin{array}{ll}0.308 & 0.0115\end{array}$

$0.281 \quad 0.0168$

$0.045 \quad 0.0005$

$0.065 \quad 0.0004$

$0.064 \quad 0.0015$

$0.101 \quad 0.0166$

$0.084 \quad 0.0030$

$0.133 \quad 0.0070$

$0.149 \quad 0.0311$

$\begin{array}{ll}0.246 & 0.0226\end{array}$

$\begin{array}{ll}0.156 & 0.0074\end{array}$

$0.048 \quad 0.0020$

$\begin{array}{lll}0.370 & 0.0192\end{array}$

0.2390 .0201

$\begin{array}{ll}0.252 & 0.0045\end{array}$

$\begin{array}{ll}0.250 & 0.0209\end{array}$

$0.044 \quad 0.0001$

$0.229 \quad 0.0208$

$0.208 \quad 0.0055$ $\begin{array}{ll}0.233 & 0.0012\end{array}$

$19 q 13$

13

$\mathrm{X}$

6

20

1

19

$\mathrm{X}$

20

15

14

$8 \mathrm{q} 22.2$

10

19

3

19

11

1

11

11

12

17

5

11q25

5

3

$\mathrm{X}$

5

7

16

7

X

X

4

15

3

1

6

$11 \mathrm{p} 15$

5

20

19

$\begin{array}{lrrrll}3.22 & 0.450 & 0.0006 & 2 & & \text { miR-378c } \\ 2.58 & 1.002 & 0.0052 & 9 & & \text { miR-377-5p } \\ 2.41 & 0.441 & 0.0017 & 19 & \text { miR-517-5p } \\ 2.28 & 0.423 & 0.0034 & 21 & \text { miR-183-3p }\end{array}$

SD P-value Location
Table II. Continued.

\begin{tabular}{lcccc}
\hline Name & $\begin{array}{c}\text { Fold-change } \\
\text { (treated/control) }\end{array}$ & SD & P-value & Location \\
\hline miR-4444 & 0.40 & 0.118 & 0.0455 & 2 \\
miR-378c & 0.40 & 0.091 & 0.0055 & 10 \\
miR-377-5p & 0.38 & 0.203 & 0.0325 & 14 \\
miR-378i & 0.37 & 0.120 & 0.0014 & 22 \\
miR-517-5p & 0.36 & 0.274 & 0.0225 & 19 \\
miR-183-3p & 0.34 & 0.180 & 0.0222 & 7 \\
\hline
\end{tabular}

amiRNAs were matched to miRNAs extracted from cells treated with $5 \mathrm{mM}$ metformin for 1 week as shown in Table I. miRNAs, microRNAs; HPrAD-vis, human visceral preadipocytes; SD, standard deviation.
Unsupervised hierarchical clustering analysis, using Pearson's correlations, showed that HPrAD-vis cells treated in vitro for 1 or 2 weeks with metformin clustered separately from the untreated cells (Fig. 2). The subset of 19 miRNAs in HPrAD-vis cells treated for 1 week with metformin and the 33 miRNAs detected in HPrAD-vis cells treated for 2 weeks were found to exhibit $>1.5$-fold alterations in the expression levels between the metformin-treated and control groups. These microarray data are registered at the NCBI Gene expression Omnibus (GEO) under accession number GSE55665.

\section{Discussion}

In the present study, metformin suppressed lipid accumulation and adiponectin secretion with no suppression of cell growth. In addition, the expression levels of PPAR $\gamma$ and $\mathrm{C} / \mathrm{EBP} \alpha$ in HPrAD-vis cells were altered following treatment, indicating that metformin suppressed the differentiation of human preadipocytes $(6,23,24)$. Additionally, the miRNA profiles of metformin-treated preadipocytes and control cells showed differential clustering. In particular, the expression of miR-1246 and miR-3687 increased following metformin administration, while the expression of miR-378 family members was decreased.

Differentiation of preadipocytes is associated with the accumulation of lipid droplets in the cells. Preadipocytes differentiate in mature fatty cells when they are exposed to an excess energy supply, such as through overnutrition (7). Mature adipocytes secrete several types of adipokines, including adiponectin (23). Additionally, the differentiation of adipocytes from mesenchymal stromal stem cells is characterized by alterations in genes such as PPAR $\gamma$ and C/EBP (25). Indeed, PPAR $\gamma$ and $\mathrm{C} / \mathrm{EBP} \alpha$ are representative of the genes upregulated in preadipocytes during the differentiation process from preadipocytes to mature adipocytes (24).

In a previous report, metformin was shown to suppress lipid droplet accumulation in murine preadipocytes (6). Similarly, in the present study, human preadipocytes showed reduced lipid accumulation without a decrease in cell numbers. Furthermore, the secretion of adiponectin, the mRNA expression of PPAR $\gamma$ and $\mathrm{C} / \mathrm{EBP} \alpha$ and the protein expression of 

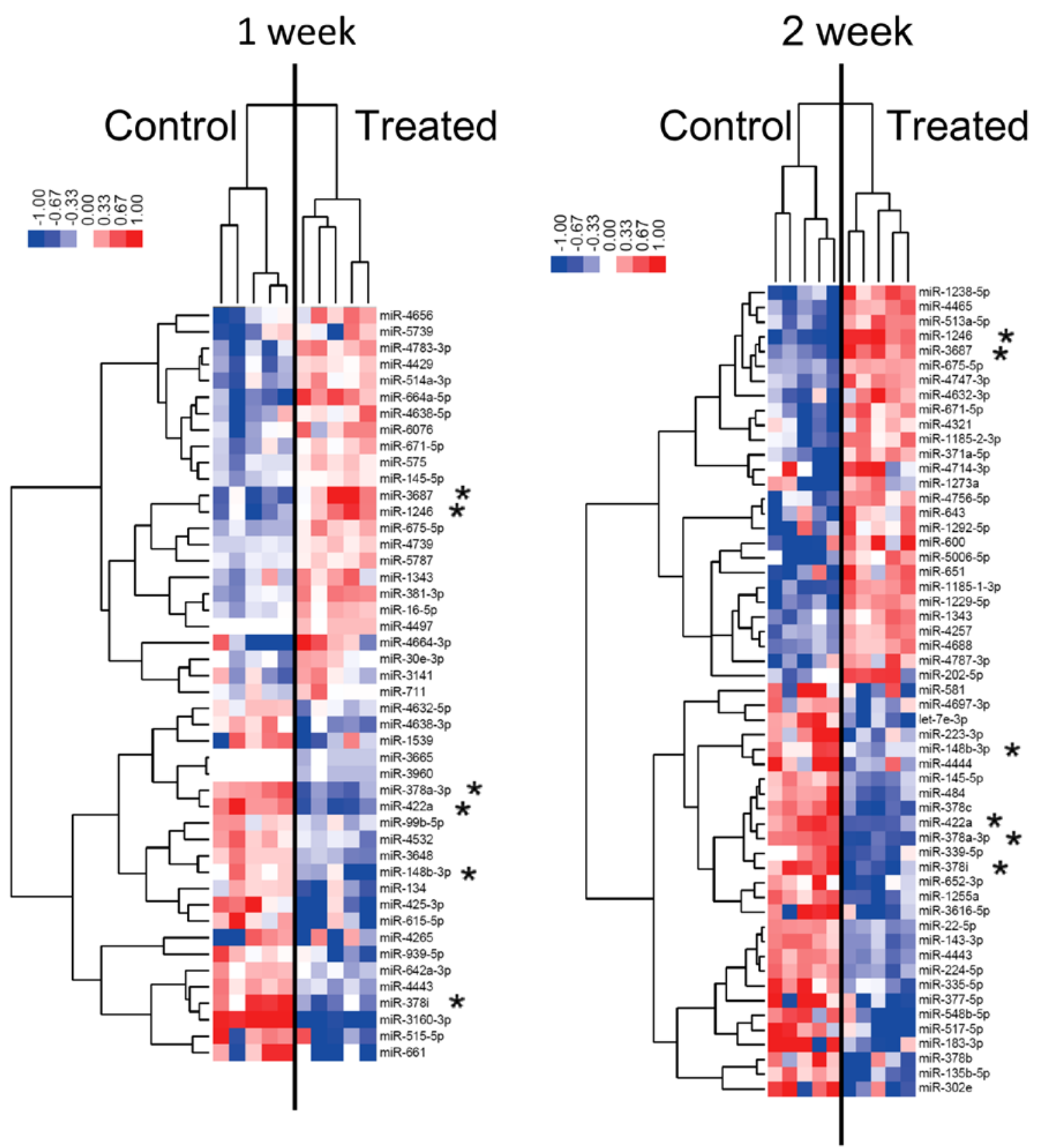

Figure 2. Hierarchical clustering of miRNAs from HPrAD-vis cells. Hierarchical clustering was performed for miRNA expression profiles of control HPrAD-vis cells and cells cultured with $5 \mathrm{mM}$ metformin for 1 (left-side panel) or 2 weeks (left-side panel). The samples are arranged in columns and miRNAs in rows. The miRNA clustering tree is shown on the left, and the sample clustering tree is shown at the top of each heat map. The heat maps show the relative expression intensity for each miRNA in which the base-2 logarithm of the intensity is median-centered for each row. The color-coding is indicated as a horizontal bar at the bottom left. The six miRNAs with an asterisk are common between data from 1 week incubation with metformin $(\mathrm{P}<0.05)$ and 2 weeks incubation with the reagent $(\mathrm{P}<0.005)$ regardless of fold-change $(\mathrm{n}=5)$. miRNAs, microRNAs; HPrAD-vis, human visceral preadipocytes.

C/EBP in human preadipocytes decreased under metformin administration, similar to previous findings on murine preadipocytes (6). Collectively, our results suggest that metformin inhibits the differentiation of human preadipocytes.

Adipocyte differentiation is regulated via miRNAs; these small non-coding RNAs target the mRNAs of genes involved in each step of the differentiation from mesenchymal stromal stem cells to mature adipocytes (26). miRNAs are evolutionarily endogenous non-coding RNAs that have been identified as post-transcriptional regulators of gene expression. miRNAs bind mainly to the $3^{\prime}$ untranslated regions (UTRs) of target mRNAs, resulting in mRNA degradation or the blockade of
mRNA translation $(27,28)$. Thus, miRNAs play crucial roles in the differentiation, maturation and intracellular metabolism of cells and the effects of various drugs, as shown in the findings of the present study $(13,14,16-21)$. Several miRNAs have been shown to contribute to lipid metabolism (8), with roles for miRNAs reported for lipid synthesis, metabolism, transportation and storage.

In the present study, upregulation of miR-1246 and miR-3687 and downregulation of the miR-378 family were found to be involved in the differentiation of preadipocytes.

Mice genetically lacking miR-378 family members are known to be resistant to high-fat diet-induced obesity (10). 
In addition, miR-378 family members were found to be downregulated in murine preadipocytes, the differentiation of which was suppressed by metformin treatment (29). Therefore, metformin may exert its inhibitory effect on visceral adipocytes via downregulation of the miR-378 family.

Our data further suggest that the upregulation of miR-1246 and miR-3687 and downregulation of miR-422a are associated with the effect of metformin on the inhibition of preadipocyte differentiation. To the best of our knowledge, this report is the first to describe the association between three miRNAs above and lipid metabolism. Notably, mice and rats lack miR-1246, miR-3687 or miR-422a. Thus, the murine in vitro model was not used to examine the expression levels of these miRNAs following metformin treatment. The significance of miR-1246, miR-3687 and miR-422a in adipogenesis and the maturation of preadipocytes thus remains to be investigated.

In a previous study, miR-137 was shown to play a role in the differentiation of preadipocytes (30). However, our results showed that miR-137 expression was not altered during the differentiation of preadipocyte cells. Thus, the role of miR-137 in preadipocyte maturation should be investigated further in future studies.

In conclusion, metformin suppresses the maturation of human preadipocytes in vitro and altered the miRNA profile of cells. In particular, our results identify miR-1246, miR-3687 and $\mathrm{miR}-422 \mathrm{a}$ as promising therapeutic targets for the treatment of visceral obesity.

\section{References}

1. Kaur J: A comprehensive review on metabolic syndrome. Cardiol Res Pract 2014: 943162, 2014.

2. Al-Daghri NM, Al-Attas OS, Alokail MS, Alkharfy KM, Charalampidis P, Livadas S, Kollias A, Sabico SL and Chrousos GP: Visceral adiposity index is highly associated with adiponectin values and glycaemic disturbances. Eur J Clin Invest 43: 183-189, 2013.

3. Simmons RK, Alberti KG, Gale EA, Colagiuri S, Tuomilehto J, Qiao Q, Ramachandran A, Tajima N, Brajkovich Mirchov I, et al: The metabolic syndrome: Useful concept or clinical tool? Report of a WHO Expert Consultation. Diabetologia 53: 600-605, 2010

4. O'Brien PE, MacDonald L, Anderson M, Brennan L and Brown WA: Long-term outcomes after bariatric surgery: Fifteen-year follow-up of adjustable gastric banding and a systematic review of the bariatric surgical literature. Ann Surg 257: 87-94, 2013.

5. Inzucchi SE, Bergenstal RM, Buse JB, Diamant M, Ferrannini E, Nauck M, Peters AL, Tsapas A, Wender R and Matthews DR: Management of hyperglycaemia in type 2 diabetes: A patient-centered approach. Position statement of the American Diabetes Association (ADA) and the European Association for the Study of Diabetes (EASD). Diabetologia 55: 1577-1596, 2012.

6. Alexandre KB, Smit AM, Gray IP and Crowther NJ: Metformin inhibits intracellular lipid accumulation in the murine pre-adipocyte cell line, 3T3-L1. Diabetes Obes Metab 10: 688-690, 2008

7. Liang J, Fu M, Ciociola E, Chandalia M and Abate N: Role of ENPP1 on adipocyte maturation. PLoS One 2: e882, 2007.

8. Fernández-Hernando C, Ramírez CM, Goedeke L and Suárez Y: MicroRNAs in metabolic disease. Arterioscler Thromb Vasc Biol 33: 178-185, 2013.

9. Gao Y, Xue J, Li X, Jia Y and Hu J: Metformin regulates osteoblast and adipocyte differentiation of rat mesenchymal stem cells. J Pharm Pharmacol 60: 1695-1700, 2008.

10. Carrer M, Liu N, Grueter CE, Williams AH, Frisard MI, Hulver MW, Bassel-Duby R and Olson EN: Control of mitochondrial metabolism and systemic energy homeostasis by microRNAs 378 and 378*. Proc Natl Acad Sci USA 109: 15330-15335, 2012.
11. Wilson B, Liotta LA and Petricoiniii E: Dynamic protein pathway activation mapping of adipose-derived stem cell differentiation implicates novel regulators of adipocyte differentiation. Mol Cell Proteomics 12: 2522-2535, 2013.

12. Berg AH, Combs TP and Scherer PE: ACRP30/adiponectin: An adipokine regulating glucose and lipid metabolism. Trends Endocrinol Metab 13: 84-89, 2002.

13. Kato K, Gong J, Iwama H, Kitanaka A, Tani J, Miyoshi H, Nomura K, Mimura S, Kobayashi M, Aritomo Y, et al: The antidiabetic drug metformin inhibits gastric cancer cell proliferation in vitro and in vivo. Mol Cancer Ther 11: 549-560, 2012.

14. Fujita K, Iwama H, Sakamoto T, Okura R, Kobayashi K, Takano J, Katsura A, Tatsuta M, Maeda E, Mimura S, et al: Galectin-9 suppresses the growth of hepatocellular carcinoma via apoptosis in vitro and in vivo. Int J Oncol 46: 2419-2430, 2015.

15. Masaki T, Okada M, Tokuda M, Shiratori Y, Hatase O, Shirai M, Nishioka M and Omata M: Reduced C-terminal Src kinase (Csk) activities in hepatocellular carcinoma. Hepatology 29: 379-384, 1999.

16. Miyoshi H, Kato K, Iwama H, Maeda E, Sakamoto T, Fujita K, Toyota Y, Tani J, Nomura T, Mimura S, et al: Effect of the antidiabetic drug metformin in hepatocellular carcinoma in vitro and in vivo. Int J Oncol 45: 322-332, 2014.

17. Kobayashi M, Kato K, Iwama H, Fujihara S, Nishiyama N, Mimura S, Toyota Y, Nomura T, Nomura K, Tani J, et al: Antitumor effect of metformin in esophageal cancer: In vitro study. Int J Oncol 42: 517-524, 2013.

18. Fujimori T, Kato K, Fujihara S, Iwama H, Yamashita $\mathrm{T}$, Kobayashi K, Kamada H, Morishita A, Kobara H, Mori H, et al: Antitumor effect of metformin on cholangiocarcinoma: In vitro and in vivo studies. Oncol Rep 34: 2987-2996, 2015.

19. Fujihara S, Kato K, Morishita A, Iwama H, Nishioka T, Chiyo T, Nishiyama N, Miyoshi H, Kobayashi M, Kobara H, et al: Antidiabetic drug metformin inhibits esophageal adenocarcinoma cell proliferation in vitro and in vivo. Int $\mathrm{J}$ Oncol 46: 2172-2180, 2015.

20. Kato K, Iwama H, Yamashita T, Kobayashi K, Fujihara S, Fujimori T, Kamada H, Kobara $H$ and Masaki T: The antidiabetic drug metformin inhibits pancreatic cancer cell proliferation in vitro and in vivo: Study of the microRNAs associated with the antitumor effect of metformin. Oncol Rep 35: 1582-1592, 2016.

21. Fujita K, Kobara H, Mori H, Fujihara S, Chiyo T, Matsunaga T, Nishiyama N, Ayaki M, Yachida T, Morishita A, et al: Differences in miRNA expression profiles between GIST and leiomyoma in human samples acquired by submucosal tunneling biopsy. Endosc Int Open 3: E665-E671, 2015.

22. Bolstad BM,Irizarry RA, Astrand M and Speed TP: A comparison of normalization methods for high density oligonucleotide array data based on variance and bias. Bioinformatics 19: 185-193, 2003.

23. Nigro E, Scudiero O, Monaco ML, Palmieri A, Mazzarella G, Costagliola C, Bianco A and Daniele A: New insight into adiponectin role in obesity and obesity-related diseases. BioMed Res Int 2014: 658913, 2014.

24. Wu Z, Rosen ED, Brun R, Hauser S, Adelmant G, Troy AE, McKeon C, Darlington GJ and Spiegelman BM: Cross-regulation of C/EBP alpha and PPAR gamma controls the transcriptional pathway of adipogenesis and insulin sensitivity. Mol Cell 3: 151-158, 1999.

25. Nakagami $\mathrm{H}$ : The mechanism of white and brown adipocyte differentiation. Diabetes Metab J 37: 85-90, 2013.

26. Son YH, Ka S, Kim AY and Kim JB: Regulation of adipocyte differentiation via MicroRNAs. Endocrinol Metab (Seoul) 29: 122-135, 2014.

27. Callegari E, Elamin BK, Sabbioni S, Gramantieri L and Negrini M: Role of microRNAs in hepatocellular carcinoma: A clinical perspective. Onco Targets Ther 6: 1167-1178, 2013.

28. Kerr TA, Korenblat KM and Davidson NO: MicroRNAs and liver disease. Transl Res 157: 241-252, 2011.

29. Gerin I, Bommer GT, McCoin CS, Sousa KM, Krishnan V and MacDougald OA: Roles for miRNA-378/378* in adipocyte gene expression and lipogenesis. Am J Physiol Endocrinol Metab 299: E198-E206, 2010.

30. Shin KK, Kim YS, Kim JY, Bae YC and Jung JS: miR-137 controls proliferation and differentiation of human adipose tissue stromal cells. Cell Physiol Biochem 33: 758-768, 2014. 